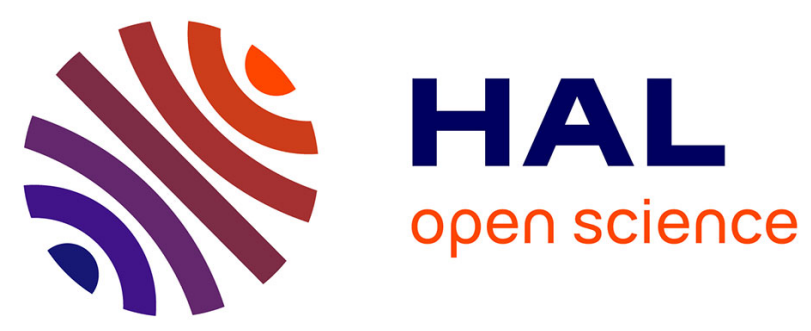

\title{
Contact-dependent reproducible hypomania induced by Deep Brain Stimulation in Parkinson's disease: Clinical, anatomical and functional imaging study
}

Ulla Miguel, Stephane C Thobois, Pierre-Michel Llorca, Philippe P Derost, Jean-Jacques Lemaire, Isabelle Chereau-Boudet, Ingrid de Chazeron, Audrey Schmitt, Benedicte Ballanger, Emmanuel Broussolle, et al.

\section{To cite this version:}

Ulla Miguel, Stephane C Thobois, Pierre-Michel Llorca, Philippe P Derost, Jean-Jacques Lemaire, et al.. Contact-dependent reproducible hypomania induced by Deep Brain Stimulation in Parkinson's disease: Clinical, anatomical and functional imaging study. Journal of Neurology, Neurosurgery and Psychiatry, 2010, 82 (6), pp.607. 10.1136/jnnp.2009.199323 . hal-00591165

\section{HAL Id: hal-00591165 \\ https://hal.science/hal-00591165}

Submitted on 7 May 2011

HAL is a multi-disciplinary open access archive for the deposit and dissemination of scientific research documents, whether they are published or not. The documents may come from teaching and research institutions in France or abroad, or from public or private research centers.
L'archive ouverte pluridisciplinaire HAL, est destinée au dépôt et à la diffusion de documents scientifiques de niveau recherche, publiés ou non, émanant des établissements d'enseignement et de recherche français ou étrangers, des laboratoires publics ou privés. 


\title{
Contact-dependent reproducible hypomania induced by Deep Brain Stimulation in Parkinson's disease: Clinical, anatomical and functional imaging study
}

\author{
Miguel Ulla MD ${ }^{1,2}$, Stéphane Thobois MD, $\mathrm{PhD}^{3,4,5}$, Pierre-Michel Llorca MD, $\mathrm{PhD}^{2,6}$, \\ Philippe Derost MD ${ }^{1,2}$, Jean-Jacques Lemaire MD, $\mathrm{PhD}^{7}$, Isabelle Chereau-Boudet MD ${ }^{2,6}$, \\ Ingrid de Chazeron $\mathrm{PhD}^{2}$, Audrey Schmitt MD ${ }^{6}$, Bénédicte Ballanger $\mathrm{PhD}^{3,4,5}$ \\ Emmanuel Broussolle MD, $\mathrm{PhD}^{3,4,5}$ and Franck Durif $\mathrm{MD}, \mathrm{PhD}^{1,2}$.
}

Corresponding author:

Miguel Ulla, MD

Service de Neurologie A

Hôpital Gabriel Montpied

58, rue Montalembert, CHU Clermont-Ferrand

F-63000 Clermont-Ferrand (France)

Telephone: +33473751594

Fax number: +33 473751596

Keywords:

Parkinson's disease

Mania

Deep-brain stimulation

Subthalamic nucleus

Substantia nigra

Affiliations:

1 : CHU Clermont-Ferrand, Service de Neurologie A, Clermont-Ferrand, France

2 : Univ Clermont 1, EA3845, Clermont-Ferrand, France

3 : Université Lyon I, Faculté de médecine Lyon Sud Charles Mérieux, Lyon, France ;

4 : Hospices Civils de Lyon, Hôpital Neurologique Pierre Wertheimer, Lyon, France

5 : CNRS, Centre de Neurosciences Cognitives, UMR 52-29, Bron, France.

6 : CHU Clermont-Ferrand, Service de Psychiatrie B, Clermont-Ferrand, France

7 : CHU Clermont-Ferrand, Service de Neurochirurgie A, Clermont-Ferrand, France.

Word count: 3872 words 


\section{Licence for Publication}

I, Miguel ULLA, the Corresponding Author of this article "Contact-dependent reproducible hypomania induced by Deep Brain Stimulation in Parkinson's disease: Clinical, anatomical and functional imaging study" has the right to grant on behalf of all authors and does grant on behalf of all authors, a licence to the BMJ Publishing Group Ltd and its licensees, to permit this Contribution (if accepted) to be published in Journal of Neurology, Neurosurgery and Psychiatry (JNNP) and any other BMJ Group products and to exploit all subsidiary rights, as set out in our licence set out at: (http://jnnp.bmj.com/site/about/licence.pdf)

Please tick one or more boxes as appropriate:

$\square$ I am the sole author of the Contribution.

$X$ : I am one author signing on behalf of all co-owners of the Contribution.

$\square$ The Contribution has been made in the course of my employment and I am signing as authorised by my employer.

$\square$ I am a US Federal Government employee acting in the course of my employment.

$\square$ I am not a US Federal Government employee, but some or all of my co-authors are.

$\square$ I am an employee of the UK Government acting in the course of my employment

$\square$ I am not an employee of the UK Government acting in the course of my employment but some/all of my co-authors are.

List of the names and email addresses of all co-authors:

Miguel Ulla, mulla@chu-clermontferrand.fr

Stéphane Thobois, stephane.thobois@chu-lyon.fr

Pierre-Michel Llorca, pmllorca@ chu-clermontferrand.fr

Philippe Derost, pderost@ chu-clermontferrand.fr

Jean-Jacques Lemaire, jilemaire@ chu-clermontferrand.fr

Isabelle Chereau-Boudet, ichereau@ chu-clermontferrand.fr

Ingrid de Chazeron, idechazeron@ @ chu-clermontferrand.fr

Audrey Schmitt, aschmitt@ chu-clermontferrand.fr

Bénédicte Ballanger, benedicte.ballanger@isc.cnrs.fr

Emmanuel Broussolle, emmanuel.broussolle@ chu-lyon.fr

Franck Durif, fdurif@chu-clermontferrand.fr 


\section{Abstract}

Hypomanic symptoms depending on anatomical location of contacts are reported in Parkinson's disease (PD) patients treated by deep-brain-stimulation (DBS) of subthalamic nucleus (STN) area. However, the underlying cortical and subcortical dysfunction remains debated. In this study, we investigated five PD patients implanted with DBS-STN who presented reversible and reproducible hypomanic symptoms after stimulation of specific "manic" contacts. Hypomanic symptoms were assessed using the Bech and Rafaelsen Mania Scale (MAS). A 3-D anatomical location of "euthymic" and "manic" contacts, after matching post operative CT scan with pre-operative stereotactic MRI, and a $\mathrm{H}_{2}{ }^{15} \mathrm{O}$ PET study in conditions testing "euthymic" and "manic" contacts, were performed.

In the "euthymic" condition, MAS score (mean \pm SD) was $0.6 \pm 0.5$ compared to $7.8 \pm 3.1$ in the "manic" condition. Nine of ten "manic" contacts were located in the substantia nigra mainly in its ventral part. PET showed that hypomania was associated with a strong asymmetrical cerebral activation involving preferentially the right hemisphere, and was mediated by an activation of the anterior cingulate and medial prefrontal cortex.

The present study demonstrates the role of subcortical structures in the genesis of hypomania in PD patients treated with DBS and stresses the implication of substantia nigra. 


\section{INTRODUCTION}

Deep brain stimulation of the subthalamic nucleus (STN-DBS), now considered as the "gold standard" technique to treat motor symptoms in advanced PD patients, can also affect executive functions (1) and induce behavioral changes and psychiatric disorders (2). A recent meta-analysis (3) estimates the percentage of manic complications between 0.9 and $1.7 \%$, which is probably underestimated due to the transient character of the symptomatology. Indeed the manic symptoms are often described in the immediate postoperative period and last a few hours or days $(4,5)$. Manic and depressive symptoms strictly induced by the stimulation of specific active contacts using precise stimulation parameters have also been reported rarely (6-8). All these observations suggest that the STN area plays a role in mood control. However, several questions remain unresolved regarding the manic symptoms induced by STN-DBS. In particular, mood symptomatology is frequently only poorly described. Moreover, there is no consensus on the structures responsible for the manic symptoms induced by DBS (STN or substantia nigra (SN)). Finally, functional imaging has been performed on only three patients with discrepancies in the findings $(7,8)$.

The present study aims at investigating the pathophysiology of hypomania in PD patients treated by bilateral STN-DBS using blinded and randomized psychiatric evaluation, 3D anatomical location of stimulation contacts and functional imaging by $\mathrm{H}_{2}{ }^{15} \mathrm{O}$ positron emission tomography (PET). 


\section{METHODS}

\section{Patient's selection}

Patients were selected among the 113 PD patients implanted for STN-DBS in the Movement Disorders Unit of Clermont-Ferrand University Hospital between 1994 and 2006. Surgical selection, procedure and standardized postoperative follow-up were described in supplement data.

Among the surgically implanted cases, we identified retrospectively PD patients with hypomanic or manic symptoms that were signaled in the postoperative period. Symptoms consisted in transient hypomanic manifestations seen just after surgery and lasting a few hours or days, or in acute manic manifestations observed during the setting of stimulation parameters such as the change of active contacts or increase of voltage. Psychiatric symptoms included: diurnal and/or nocturnal hyperactivity, insomnia, compulsive buying, increased sexual preoccupations, mood liability, and tachypsychia. Only patients with a manic or hypomanic state, as adapted from DSM-IV (detailed below) (9), which was induced in a reversible and reproducible manner by the stimulation of specific contacts were definitely included in this study. Demented patients and subjects with past history of bipolar disorder were excluded. For selected patients, several tests were performed, using the Bech and Rafaelsen Mania Scale (MAS) (detailed below)(10). The "euthymic" stimulation condition was bilateral and led to the best motor improvement without mood disorders and other side effects. The "manic" stimulation condition was bilateral and led to sustained elevated mood (> 1 hour) at a minimum voltage (maximum $4 \mathrm{~V}$ ). Assessments were completed by two neurologists in an open fashion (MU, PD).

The study protocol was approved by the Ethics Committee of Clermont-Ferrand University Hospital (File AU 631), and all patients gave their written informed consent. 


\section{Psychiatric double-blind assessment}

The diagnosis of hypomania was made according to the DSM-IV criteria using the MiniInternational Neuropsychiatric Interview (MINI) (11) for affective disorders. To dimensionally assess the intensity of the hypomanic symptoms, the MAS(10) was used. These tools had to be adapted due to the experimental conditions (for details, see supplement data). The MINI and MAS were assessed in a double-blind fashion by a trained psychiatrist (ICB, AS) in "euthymic" and "manic" condition in the morning. The order of the stimulation conditions was randomized. Each condition was tested during approximately 1 hour. The latency of the mood changes was usually less than 5 minutes. The psychiatric assessment was performed about 30 minutes after the contacts had been modified, leaving enough time to observe any clear-cut change in patient's mood. Patients took their usual daily antiparkinsonian treatment when tested. The next day, motor efficacy using the motor part of the Unified Parkinson Disease Rating Scale (UPDRS part III) (12) of acute STN-DBS after a 12-hour withdrawal of antiparkinsonian medication was assessed in three stimulation conditions: bilateral off stimulation (stim off), "euthymic" condition and "manic" condition.

\section{Anatomical location of contacts}

The preoperative outlining and labeling of subthalamic structures were achieved through a step by step approach starting from the identification of simple shaped and located structures such as SN and STN revealed by the spontaneous contrasts between white and grey matters visible on the stereotactic MRI (13). The anatomical location of the four contacts was determined after matching post operative imaging with pre-operative stereotactic MRI (Mutual information algorithm; Iplan, BrainLab, Germany) (for details, see supplement data). After matching, the anatomical location was determined contact by contact, for each patient, in a 3D anatomical environment (illustrated in Figure 1). The percentage of the contact within the SN and STN was determined visually using a semi-quantitative scale $(100 \%, 75 \%, 50 \%$ 
and $25 \%$ ) (14). For a percentage of $100 \%$, the contact was considered "totally" within the structure. A percentage below indicated that the contact was "partially" within the structure and $0 \%$ that contact was outside the structure.

\section{PET study}

PET scanning was performed at the CERMEP-Imagerie du vivant (PET imaging center, Lyon, France) on a CTI HR+ Siemens tomograph (CTI/ Siemens, Knoxville, Tennessee, USA). Images were acquired and reconstructed using a protocol previously described (15).

Tasks

Subjects lay down on the bed of the PET scanner with their eyes closed. Two conditions were considered: execution of an attentional task (T), and rest $(\mathrm{R})$. The aim of the attentional task was to determine if stimulation on manic contacts could induce attentional disturbances that would have measurable behavioral consequences such as motor anticipation or, on the contrary, missing some stimuli. The attentional tasks consisted in moving a joystick frontward with the right hand as fast as possible after hearing an auditory cue, which occurred at variable intervals for a fixed total number of 15 high tone stimuli during 120 seconds. This is a reaction task, whose aim is to maintain attention to action and which has been used in several imaging studies $(16,17)$. In the rest condition, subjects held the joystick in their right hand, heard the auditory cue but did not move their hand. Each task was repeated three times for a total of 6 scans. The order of conditions was counterbalanced. The scans were acquired in each stimulation conditions. The first block (i.e. 6 scans) was performed under "euthymic" condition $\left(\mathrm{T}_{\mathrm{Eu}}\right.$ and $\mathrm{R}_{\mathrm{Eu}}$ ). The stimulation contacts were then changed (from "euthymic" to "manic") and after 30 minutes the next 6 scans were acquired ( $\mathrm{T}_{\mathrm{Man}}$ and $\mathrm{R}_{\mathrm{Man}}$ ), leading to a total of 12 scans. 


\section{Behavioral analysis}

During the PET, movement duration and reaction time (interval from beep to movement) were computed for the motor task.

\section{Statistical analysis}

\section{Clinical and anatomical location data analyses}

Comparison of MAS total and items scores, in euthymic and manic condition and comparisons of voltages according to stimulation condition were performed using a paired $\mathrm{t}$ test. A Friedman test was performed and followed by a Tukey test if previous tests were significant in order to compare the motor effects of levodopa and stimulation using the UPDRS part III and to compare the daily dosage of dopaminergic treatment pre- and postoperatively. Adjustments for multiple comparisons were performed using Tukey's HSD tests.

\section{Behavioral analysis}

A within one-way ANOVA design was used to identify significant differences between experimental conditions. Data from all responses were incorporated into this ANOVA analysis. Duncan's multiple range tests was used for post-hoc comparisons of the means.

\section{PET data analysis}

Images processing (realignment, normalization, smoothing) was performed as previously described using Statistical Parametric Mapping software (SPM 2, Wellcome Department of Cognitive Neurology, MRC Cyclotron Unit, London, UK) (15). Variations in global flow across subjects were removed by proportionally scaling each image to have an arbitrary level of $50 \mathrm{ml} / 100 \mathrm{ml} / \mathrm{min}$. rCBF changes were statistically analyzed for all voxels exceeding $80 \%$ of the mean value of the scan. We first analyzed the main effect of stimulation condition. Then, for each condition, (rest and task) we determined the simple effect of stimulation condition. Finally, we assessed the effects of stimulation condition changes by interaction 
analysis. The level of significance was set at family wised error (FWE) corrected $p<0.05$ for a minimal cluster size of 10 voxels. During PET experiment, movement duration and reaction time (interval from beep to movement) were computed for the motor task (for details, see supplement data).

\section{RESULTS}

\section{Patient characteristics and neurological assessment}

Eleven patients were initially selected. Six were excluded for the following reasons: two presented dementia at the time of study, one had a history of bipolar disorder before surgery, two had no reproducible mania, and one could not comply with instructions due to behavioral disorder. Five patients were finally included in the study. Patient 1 had already been presented as a single case report (8).

All patients but one (patient 2, ambidextrous) were right-handed according to Edinburgh Handedness Inventory. (18).Their demographic and clinical data are provided in table 1 . The stimulation parameters of the "euthymic" and "manic" conditions are presented in table 2 . The psychiatric interview did not reveal any premorbid personality.

After 6 months, post operative evaluation showed that the 5 patients benefited of STN-DBS with an improvement in UPDRS III of 58\% on average (range: $41-66 \%$ ). The effect of STNDBS was maintained at study time except for patient 1 due to emergence of parkinsonian axial signs notably dysarthia and freezing of gait.

One patient was on levodopa monotherapy, three patients had an association of levodopa and dopaminergic agonist, and one was receiving levodopa, entacapone and dopamine agonist. Medications associations remained unchanged throughout follow-up. At the time of the study, the antiparkinsonian treatment, calculated as levodopa-equivalent doses (LED)(19), was lower 
than before surgery (table 1), and was stable for at least 6 months. Patients did not receive any psychotropic treatment during the study. 
Table 1: Patient characteristics, motor disability assessment and antiparkinsonian treatment

\begin{tabular}{|c|c|c|c|c|c|c|c|c|c|c|c|c|c|c|c|c|c|c|}
\hline \multirow[b]{2}{*}{ Patient } & \multirow[b]{2}{*}{ Sex } & \multirow[b]{2}{*}{ Age (years) } & \multirow[b]{2}{*}{$\begin{array}{c}\text { Disease } \\
\text { duration } \\
\text { (years) }\end{array}$} & \multicolumn{4}{|c|}{ Pre operative evaluation } & \multicolumn{5}{|c|}{ Post operative 6 months evaluation } & \multicolumn{6}{|c|}{ Evaluation at study time } \\
\hline & & & & Mattis & $\begin{array}{l}\text { UPDRS III } \\
\text { med off }\end{array}$ & $\begin{array}{l}\text { UPDRS III } \\
\text { med on }\end{array}$ & $\begin{array}{l}\text { LED } \\
\text { (mg/day) }\end{array}$ & $\begin{array}{l}\text { UPDRS III } \\
\text { med off/ stim } \\
\text { off }\end{array}$ & $\begin{array}{l}\text { UPDRS III } \\
\text { med off/stim } \\
\text { on }\end{array}$ & $\begin{array}{l}\text { UPDRS III } \\
\text { med on/ } \\
\text { stim off }\end{array}$ & $\begin{array}{l}\text { UPDRS III } \\
\text { med on/ } \\
\text { stim on }\end{array}$ & $\operatorname{LED}(\mathrm{mg} / \mathrm{day})$ & $\begin{array}{l}\text { Study time } \\
\text { from surgery } \\
\text { (years) }\end{array}$ & Mattis & $\begin{array}{l}\text { UPDRS III } \\
\text { med off/ stim } \\
\text { off }\end{array}$ & $\begin{array}{l}\text { UPDRS III } \\
\text { med off/ stim } \\
\text { "euthymic" }\end{array}$ & $\begin{array}{l}\text { UPDRS III } \\
\text { med off/ } \\
\text { stim "manic" }\end{array}$ & $\begin{array}{l}\text { LED } \\
\text { (mg/day) }\end{array}$ \\
\hline 1 & $\mathrm{~F}$ & 58 & 10 & 142 & 29 & 5 & 725 & 41 & 24 & 21 & 13 & 150 & 2 & 141 & 39 & 36 & 37 & 650 \\
\hline 2 & M & 73 & 7 & 143 & 30 & 6 & 493 & 22 & 7.5 & 5 & 2.5 & 300 & 3 & 144 & 33.5 & 11.5 & 27.5 & 350 \\
\hline 3 & M & 63 & 6 & 138 & 20.5 & 7 & 1500 & 22 & 8.5 & 5.5 & 14.5 & 500 & 6 & 138 & 41 & 18 & 24.5 & 1100 \\
\hline 4 & $\mathrm{~F}$ & 53 & 7 & 133 & 23 & 5 & 700 & 9.5 & 3.5 & 2.5 & 2.5 & 225 & 5 & 142 & 31 & 15 & 15 & 375 \\
\hline 5 & $\mathrm{M}$ & 63 & 14 & 143 & 23 & 6 & 1812 & 36 & 12 & 5 & 4 & 768 & 5 & 143 & 36.5 & 24 & 47 & 1450 \\
\hline Iean $( \pm$ SD & & $62 \pm 7.4$ & $8.8 \pm 3.3$ & $140 \pm 4$ & $25.1 \pm 4.2 *$ & $5.8 \pm 0.8^{*}$ & $1046 \pm 575^{* *}$ & $26.1 \pm 12.5^{\#}$ & $11.1 \pm 7.8^{\#}$ & $7.8 \pm 7.5$ & $7.3 \pm 5.9$ & $389 \pm 249^{* *} . \# \#$ & $4.2 \pm 1.6$ & $141 \pm 1$ & $36.2 \pm 4^{\S}$ & $20.9 \pm 9.6^{8}$ & $28.2 \pm 15.7$ & $785 \pm 479^{\text {\#\# }}$ \\
\hline
\end{tabular}

Patient characteristics, motor disability assessment and antiparkinsonian treatment (doses expressed in Levodopa-equivalent doses (LED), calculated on the basis of correspondences adapted from Thobois (19)) in standardized surgical follow-up (preoperative and at the 6-months assessment) and at the time of study. Mattis: Mattis dementia rating scale (20).UPDRS III: motor part of UPDRS (max=108 points). Med off: after at least a 12-hour withdrawal of antiparkinsonian treatment. All UPDRS evaluations at study time were med off. Med on: evaluation after taking 1.5 times the usual morning levodopa dose. Stim off: stimulator stopped. Stim on: stimulator activated.

*: acute effect of levodopa, $p=0.01$.

**: decreasing LED, $p=0.04$.

\#: acute effect of stimulation in the 6-month postoperative assessment, $p<0.01$.

\#\#: increasing LED, $p=0.04$

$\S:$ acute effect of stimulation under the "euthymic" condition, $p<0.01$.

Effect of acute stimulation under the "manic" condition is not significant.

(Tukey multiple comparison test). 


\section{Psychiatric double-blind assessment}

\section{Characterization of the patients using the DSM-IV criteria}

In "euthymic" condition, no manic symptoms were observed. In "manic" condition, all 5 patients presented a hypomanic state within a few minutes after the change of stimulation contacts. They all presented an elevated mood, were more talkative, and expressed an inflated self-esteem, flight of ideas and distractibility. None of the patients in "manic" condition showed marked psychomotor agitation. This state was accompanied by indisputable difficulties in subject functioning. These disturbances were considered as evident by the caregivers. The hypomanic symptoms remained stable as long as the patients were stimulated on specific "manic" contacts. Interestingly, unilateral stimulation was sufficient to induce hypomanic state in patients 3 and 5, while patients 1,2 and 4 needed bilateral stimulation. These results were obtained during the selection visit in an open fashion but were not included in the double blind protocol because of its long duration.

Dimensional evaluation using the MAS

In the "euthymic" condition, MAS score (mean \pm SD) was $0.6 \pm 0.5$ (range $0-1$ ) compared to $7.8 \pm 3.1$ (range 5-13) in the "manic" condition (table 2). This difference was statistically significant ( $\mathrm{p}<0.01)$. According to Bech (21), a score of 10/44 represents a state of "doubtful mania" and a score below 5 indicates "no mania". Consequently, 4 of our patients in "manic" condition could be considered as hypomanic, while patient 5, who had the highest total score, could be considered manic according to the adapted tool (MAS=13/32).

The paired t test run to individually analyze the MAS items showed a statistically significant lower score in "euthymic" condition than in "manic" condition for flight of thought and mood level $(\mathrm{p}<0.01)$, motor activity, self-esteem and contact $(\mathrm{p}<0.05)$. No change of the other items under the "manic" condition (motor activity, noise and hostility) was observed. 
Table 2: Contact numbers, voltage and total MAS scores in each condition.

\begin{tabular}{cccc|ccc} 
& \multicolumn{3}{c|}{ "euthymic" condition } & \multicolumn{3}{c}{ "manic" condition } \\
\cline { 2 - 7 } Patient & $\begin{array}{c}\text { contacts } \\
\text { numbers } \\
\text { (right/left) }\end{array}$ & $\begin{array}{c}\text { contacts } \\
\text { voltages } \\
\text { (right/left) }\end{array}$ & $\begin{array}{c}\text { MAS score } \\
\text { (total) }\end{array}$ & $\begin{array}{c}\text { contacts } \\
\text { numbers } \\
\text { (right/left) }\end{array}$ & $\begin{array}{c}\text { contacts } \\
\text { voltages } \\
\text { (right/left) }\end{array}$ & $\begin{array}{c}\text { MAS score } \\
\text { (total) }\end{array}$ \\
\hline 1 & $1 / 5$ & $2 \mathrm{~V} / 2 \mathrm{~V}$ & 0 & $0 / 4$ & $2.2 \mathrm{~V} / 2.2 \mathrm{~V}$ & 7 \\
2 & $2 / 5$ & $3.3 \mathrm{~V} / 1.9 \mathrm{~V}$ & 0 & $0 / 4$ & $2.5 \mathrm{~V} / 2.5 \mathrm{~V}$ & 8 \\
3 & $3 / 7$ & $4 \mathrm{~V} / 4 \mathrm{~V}$ & 1 & $0 / 4$ & $4 \mathrm{~V} / 4 \mathrm{~V}$ & 5 \\
4 & $2 / 5$ & $3.5 \mathrm{~V} / 2.6 \mathrm{~V}$ & 1 & $1 / 4$ & $3.5 \mathrm{~V} / 3 \mathrm{~V}$ & 6 \\
5 & $1-2 / 4-5$ & $3.2 \mathrm{~V} / 2.9 \mathrm{~V}$ & 1 & $0 / 4$ & $3.5 \mathrm{~V} / 3.5 \mathrm{~V}$ & 13 \\
\hline \multirow{2}{*}{ mean ( \pm SD) } & $2.94 \pm 0.8 \mathrm{~V}^{*}$ & $0.6 \pm 0.5^{* *}$ & & $3.09 \pm 0.7 \mathrm{~V}^{*}$ & $7.8 \pm 3.1^{* *}$
\end{tabular}

Contacts are numbered from 0 to 3 in the right hemisphere and 4 to 7 in the left hemisphere, where 0 and 4 are the deepest.

The stimulation was bipolar for patient 5 in the "euthymic" condition (the contact for cathode was 2 for the right electrode and 5 for the left electrode)" and monopolar for the other conditions and the other patients. The other stimulation parameters were identical in all conditions (frequency: $130 \mathrm{~Hz}$; pulse width: $60 \mu \mathrm{s}$ ).

*: There was no statistical difference of voltage between "euthymic" versus "manic" contacts **: $p<0.01$ (paired t test)

\section{Contact location}

"Manic" contacts were constantly more ventro-caudal than "euthymic" contacts. Nine of ten "manic" contacts were either partially $(5 / 10)$ or totally $(4 / 10)$ located in the SN in the ventral part. Only one "manic" contact in the left side was totally (patient 5) located in the STN. Considering the "euthymic" contacts, only one was partially located in the SN and three in the STN. Other contacts were located ventrally in contact to the STN (figure 2).

\section{PET results}

During PET scanning, all patients experienced hypomanic symptoms similar to the symptoms described during the formal clinical assessment when the stimulation was switched to "manic" contacts. 


\section{Main effect}

Compared to the "euthymic" condition, the "manic" condition induced increases in rCBF bilaterally in the dorsal anterior cingulate cortex (ACC; BA 24 and 32), in the right primary motor (BA 4) and medial prefrontal cortex (MPC; BA 10) and in the right globus pallidus (Figure 3), and decreases in rCBF in the left temporal cortex (BA 21, 39, 20) and bilaterally in the occipital cortex (BA 18, 19, 17).

Simple effect

At rest, compared to "euthymic" condition, the "manic" condition led to increases in rCBF bilaterally in the dorsal AAC (BA 24 and 32) and in the right primary motor (BA 4) and insula, and decreases in rCBF in the left temporal (BA 20) and occipital cortex (BA 18, 19, 17).

During the task, compared to "euthymic" condition, the "manic" condition induced increases in $\mathrm{rCBF}$ in the left dorsal AAC (BA 24 and 32) and the right MPC (BA 10), and decreases in rCBF in the left temporal (BA 39) and occipital cortex (BA 18) and cerebellum.

Interaction analysis

There was no identifiable difference of activation.

All these results are summarized in Tables 3A and 3B.

\section{Behavioral results}

There were no differences in movement duration $(592 \pm 238 \mathrm{~ms}$ "euthymic" stimulation vs $523 \pm 191 \mathrm{~ms}$ "hypomanic" stimulation; $\mathrm{p}=0.2)$ or reaction time $(524 \pm 183 \mathrm{~ms}$ "euthymic" stimulation vs $530 \pm 170 \mathrm{~ms}$ "hypomanic" stimulation; $\mathrm{p}=0.9$ ) between the "euthymic" and "hypomanic" stimulation conditions. 
Table 3A : Increased rCBF during manic state

\begin{tabular}{|c|c|c|c|c|c|c|c|c|}
\hline & \multicolumn{8}{|c|}{ stereotactic coordinates (regional maxima) } \\
\hline & Areas & Left/Right & $x$ & $y$ & $z$ & Z score & p corr voxel & $\begin{array}{c}\text { Cluster } \\
\text { size }(>10)\end{array}$ \\
\hline \multicolumn{9}{|c|}{ Main effect } \\
\hline & $\mathrm{ACC}(\mathrm{BA} 32)$ & $\mathrm{R}$ & 1 & 26 & 26 & 7.5 & $<0.0001$ & 1898 \\
\hline & ACC (BA 32-24) & & 0 & 44 & 8 & 7.2 & $<0.0001$ & \\
\hline & ACC (BA 32) & $\mathrm{L}$ & -2 & 28 & 20 & 6.5 & $<0.0001$ & 648 \\
\hline & M1 & $\mathrm{R}$ & 24 & -29 & 60 & 5.8 & $<0.0001$ & 472 \\
\hline & L. paracentral & $\mathrm{L}$ & -3 & -27 & 48 & 5.3 & 0.003 & 71 \\
\hline & MPC (BA 10) & $\mathrm{R}$ & 28 & 42 & -4 & 5.2 & 0.004 & 99 \\
\hline & Globus pallidus & $\mathrm{R}$ & 18 & 2 & -4 & 5.02 & 0.008 & 61 \\
\hline & L. paracentral & $\mathrm{R}$ & 10 & -34 & 66 & 4.75 & 0.026 & 25 \\
\hline \multicolumn{9}{|l|}{ At rest } \\
\hline & ACC (BA 32-24) & $\mathrm{R}$ & 1 & 26 & 26 & 6.24 & $<0.0001$ & 4430 \\
\hline & ACC (BA 32-24) & & 0 & 46 & 10 & 5.4 & 0.001 & \\
\hline & ACC (BA 32-24) & $\mathrm{L}$ & -3 & 30 & 18 & 5.2 & 0.001 & 700 \\
\hline & M1 & $\mathrm{R}$ & 22 & -27 & 62 & 5.25 & 0.003 & 1151 \\
\hline & Insula & $\mathrm{R}$ & 31 & -5 & 0 & 4.7 & 0.034 & 1310 \\
\hline \multicolumn{9}{|c|}{ During motor / attentional task } \\
\hline & $\mathrm{ACC}(\mathrm{BA} 32-24)$ & $\mathrm{L}$ & -1 & 39 & 9 & 6.07 & $<0.0001$ & 2090 \\
\hline & MPC (BA 10) & $\mathrm{R}$ & 26 & 37 & -4 & 4.6 & 0.044 & 906 \\
\hline
\end{tabular}


Table 3B : Decreased rCBF during manic state

\begin{tabular}{|c|c|c|c|c|c|c|c|c|}
\hline \multicolumn{9}{|c|}{ stereotactic coordinates (regional maxima) } \\
\hline & Areas & Left/Right & $x$ & $y$ & $z$ & Z score & p corr voxel & $\begin{array}{c}\text { Cluster } \\
\text { size }(>10)\end{array}$ \\
\hline \multicolumn{9}{|c|}{ Main effect } \\
\hline & $\operatorname{GTm}(\mathrm{BA} 21)$ & $\mathrm{L}$ & -59 & -52 & -6 & 6.2 & $<0.0001$ & 2278 \\
\hline & BA 19 & $\mathrm{~L}$ & -25 & -63 & 39 & 6.2 & $<0.0001$ & \\
\hline & GTm (BA 39) & $\mathrm{L}$ & -48 & -71 & 26 & 5.9 & $<0.0001$ & \\
\hline & GTi (BA 20) & $\mathrm{L}$ & -52 & -11 & -22 & 5.3 & 0.002 & 283 \\
\hline & Cerebellum & $\mathrm{L}$ & -13 & -82 & -31 & 5.4 & 0.001 & 148 \\
\hline & BA 18 & $\mathrm{~L}$ & -22 & -91 & 2 & 5.3 & 0.002 & 141 \\
\hline & BA 17 & $\mathrm{~L}$ & -24 & -91 & -8 & 5.1 & 0.005 & \\
\hline & BA 18 & $\mathrm{R}$ & 17 & -93 & 5 & 5.25 & 0.003 & 127 \\
\hline & BA 19 & $\mathrm{~L}$ & -11 & -93 & 27 & 5.1 & 0.005 & 50 \\
\hline & LPi (BA 40) & $\mathrm{L}$ & -62 & -30 & 23 & 4.92 & 0.01 & 40 \\
\hline \multicolumn{9}{|l|}{ At rest } \\
\hline & BA 19 & $\mathrm{~L}$ & -27 & -63 & 39 & 5.7 & $<0.0001$ & 5930 \\
\hline & BA 18 & $\mathrm{~L}$ & -24 & -89 & -3 & 4.67 & 0.037 & \\
\hline & BA 19 & $\mathrm{~L}$ & -59 & -52 & -6 & 5.16 & 0.004 & 1645 \\
\hline & GTi (BA 20) & $\mathrm{L}$ & -59 & -7 & -33 & 5.03 & 0.008 & \\
\hline \multicolumn{9}{|c|}{ During motor / attentional task } \\
\hline & BA 18 & $\mathrm{~L}$ & -27 & -65 & 22 & 5.42 & 0.001 & 67 \\
\hline & GTm (BA 39) & $\mathrm{L}$ & -48 & -71 & 24 & 5.36 & 0.002 & 118 \\
\hline & Cerebellum & $\mathrm{L}$ & -11 & -85 & -31 & 5.05 & 0.007 & 47 \\
\hline
\end{tabular}




\section{DISCUSSION}

The present study demonstrates that hypomanic state induced by DBS in PD involves mainly the $\mathrm{SN}$ and that this side effect is preferentially mediated by the anterior cingulate cortex.

\section{Clinical evaluation of hypomania}

All 5 patients experienced a hypomanic state during acute stimulation of the $\mathrm{SN}$ area according to DSM-IV diagnostic criteria (except for the notion of duration and for criteria E and F). For Benazzi (22) using the DSM-IV, 5 out of 9 clinical criteria indicate a diagnosis of hypomania with a specificity of $83.7 \%$ and a sensitivity of $90 \%$. All our patients presented at least 5 symptoms (expansive mood, increased self-esteem, increase of contact, flight of thought, distractibility) in the "manic" condition, confirming the diagnosis of hypomania.

This hypomanic state corresponded to DSM-IV diagnostic criteria but had several specificities that we can explore by the dimensional evaluation. Using the MAS, we found a global score (for each of the 5 patients) that exceeded the threshold of 5 , which confirmed the diagnosis of hypomania. It is important to note that we did not observe any increase in voice levels (item noise), which may be due to a direct deleterious effect of DBS on speech (23).

The scores of hostility and motor activity items that refer to the so-called "aggressive mania" did not increase in our sample(24). In terms of sub-type of mania, the mood state induced by DBS in our study could be described as "pure mania" according to the description made by Akiskal et al (25).

In a recent study (7), the diagnosis of hypomania was made according to DSM-IV criteria and patients were evaluated using the Young Mania Rating Scale (26). The first patient presented an irritable state that can be considered as a modification of the second factor of mania, while

the symptoms presented by the second patient were closer to those observed in our sample. Unfortunately, the authors did not provide a quantitative analysis of the specific clinical modifications induced by DBS. On the other hand, both their patients were given 
psychotropic drugs (Valproic acid, fluoxetine) at the time of the study, which may have affected the clinical symptomatology. Furthermore, clinical differences with our study could be explained by the location of the relevant contacts inside the STN (see below).

\section{Functional imaging reveals a dysfunction in the limbic cortex}

Overall, hypomanic states were related to an increase of rCBF bilaterally in the dorsal anterior cingulate cortex, in the right primary motor and medial prefrontal cortex and in the right globus pallidus, and a decrease of $\mathrm{rCBF}$ in the left temporal cortex and bilaterally in the occipital cortex.

Role of the right hemisphere

The first important result is the strong asymmetry of cerebral activation with a right-sided increase of $\mathrm{rCBF}$ and a left-sided decrease of $\mathrm{rCBF}$ during mania. This is consistent with the role of the right hemisphere in elevated mood states (27-30).

\section{Role of the ACC}

The present study underlines the major role of the dorsal ACC (BA 24-32) in the occurrence of mania. A similar increased activation of the ACC has been observed during hypomanic states in bipolar disorder (27, 30). Interestingly, Mayberg et al (31) recently demonstrated that the improvement of severe depression by DBS of the ventral ACC (BA 25) was associated with decreased activation in the ventral ACC (BA 25), which has been shown to mediate negative mood state, and increased activation in the dorsal ACC (BA 24) (31, 32). This suggests a dichotomy within the ACC in terms of mood regulation. The dorsal ACC has a role of maintaining attentional resources in order to monitor conflicts and select appropriate responses $(33,34)$. Thus, we could speculate that the increased $\mathrm{rCBF}$ in the dorsal ACC reflects the patient's difficulties in maintaining these attention-to-action capabilities in hypomanic states. 


\section{Dysfunction of the prefrontal cortex}

Mania was associated with a right-sided increase of $\mathrm{rCBF}$ in the medial prefrontal cortex (MPC, BA 10), which is part of the orbitofrontal cortex (OFC), a region connected to the ACC and involved in emotional processing $(29,30,35)$. This increased $\mathrm{rCBF}$ in the prefrontal cortex may indicate either a disturbance of cognitive and emotional processes or an attempt to control these disturbances. Mallet et al (7) also noted an increase of $\mathrm{rCBF}$ in the right inferior frontal cortex but at the same time a decrease in the right medial frontal cortex during STNDBS-induced mania. Differences in the site of stimulation inducing the hypomanic episode could explain these discrepancies. In bipolar disorders, manic episodes were rather associated with a decreased activation of the OFC, which is supposed to explain the disinhibition, the attentional disturbances, the euphoria and the difficulties to inhibit abnormal hyperactive behaviors observed in hypomania $(30,36)$.

The underlying disease (i.e. PD on the one hand and bipolar disorder on the other hand) could interfere with cortical activation abnormalities and explain, at least partly, these discrepancies. Indeed, in bipolar disorders, reduction of white matter density in prefrontal areas have been reported, which could play a part in/ account for the differences of prefrontal activation (37).

\section{Involvement of other brain regions}

We observed an increase of $\mathrm{rCBF}$ in the right primary motor cortex during hypomania at rest and during task. This could not be related to the movement itself as the movement was performed in reaction to the auditory cue with the right hand in both manic and euthymic conditions of stimulation. In one study, an increase of the left primary motor cortex activation was found during a time reaction task performed during a manic episode (28).

The increase of activation of the right globus pallidus in hypomanic state is in line with previous studies underlying the role of the right basal ganglia but also of the left caudate 
nucleus during mania (38). The role of the basal ganglia in the limbic loop could well explain these results.

On the other hand, decreases of activation were noted in the left temporal cortex (medial and inferior temporal cortex, BA 20, 21 and 39). During manic episodes, similar decreased activation of the temporal cortex has already been observed but in the right ventral temporal lobe (39). In Mallet et al study (7), a decrease of rCBF in the left superior temporal lobe was found but at the same time, $\mathrm{rCBF}$ increased in the right medial and superior temporal lobe when patients were in manic state. In the same vein, in bipolar patients, mania was associated with an increase of activation in the right temporal cortex, which was proportional to the degree of the manic state (38). In addition, previous data have shown increases of rCBF in the temporal cortex in depression, which could reflect abnormal perception of negative findings (40). Therefore, all these data are difficult to put together but it can be speculated that, to a certain point, the right temporal cortex is involved in positive mood states whereas the left temporal cortex is involved in negative mood states $(7,38,40)$. Finally, a bilateral deactivation of the occipital and parietal cortex was observed during hypomania that was also found by Mallet et al (7). This reduction of activation involved in particular the cuneus and could be explained by attentional disorders during manic episodes (41).

\section{Anatomical location of contacts involved in hypomania}

Even if the mechanisms of action of STN stimulation remains under discussion $(42,43)$, it is admitted that DBS modulates not only directly neurons and axons, notably the afferent axons projecting to STN (44), but also close structures due to the diffusion of current from the stimulated contact $(45,46)$. In our study, $9 / 10$ contacts inducing hypomania were within the $\mathrm{SN}$, ventrally, and probably in the $\mathrm{SNr}$ (47) (Figure 2, top view).

Thus stimulation in the $\mathrm{SN}$ area could have influenced the ACC via a modulation of limbic system, either cortical-subcortical limbic loop or mesocorticolimbic pathway $(48,49)$. 
Mania could also be directly related to an effect of DBS on the STN, which is divided into sensorimotor (dorsolateral), associative and limbic (medioventral) territories, at least in the non-human primates. This may notably be the case for patient 5, who exhibited the highest score of mania when stimulated on a contact located within the STN. The role of the STN is supported by a recent study in which hypomanic state was induced by stimulation of contacts located within the STN (7).

In our patients, however, (apart for patient 5 on one side), this hypothesis is probably not univocal due to the relatively large distance between the "manic" contacts and the medioventral part of the STN if we suppose a maximal $2 \mathrm{~mm}$ current diffusion from the active contacts (45) (Figure 2, top view). Besides, the differential mood effects induced by the two contacts separated by only $0.5 \mathrm{~mm}$ (notably patient 1 and 4 ) is in favor of a local effect within SN area. In addition, stimulation of "manic" contacts mainly located in the SN area induced a non-significant improvement of UPDRS III whereas stimulation of "euthymic" contacts, located higher and more dorsally in the STN area led to a significant improvement close to $50 \%$ on average. Taken together, these data suggest that manic manifestations can be elicited by several sites of stimulation located at different levels of the limbic loop. The present study emphasizes the key role of the SN for the induction of hypomania but does not rule out a participation of the STN.

In conclusion, this study demonstrates that: 1) DBS of the SN area can reproducibly induce a characteristic hypomanic state; 2) the contacts responsible for this hypomanic behavior are located mainly in the $\mathrm{SN} ; 3$ ) this hypomania is mediated by a dysfunction of the limbic system, particularly the ACC and the medial prefrontal cortex. 


\section{Acknowledgment}

Our deep thanks to Pr Philippe Courtet for reading this manuscript and Nicolas Coste for PET data corrections. We are indebted to Mrs P. Martin-Maillot for English corrections.

\section{Disclosure}

The authors state no conflict of interest.

\section{Funding}

This work was supported by grant PHRC 2005 from the Programme Hospitalier de Recherche Clinique. 


\section{REFERENCES}

1. Witt K, Daniels C, Reiff J, Krack P, Volkmann J, Pinsker MO, et al. Neuropsychological and psychiatric changes after deep brain stimulation for Parkinson's disease: a randomised, multicentre study. Lancet Neurol. $2008 \mathrm{Jul} ; 7(7): 605-14$.

2. Houeto JL, Mesnage V, Mallet L, Pillon B, Gargiulo M, du Moncel ST, et al. Behavioural disorders, Parkinson's disease and subthalamic stimulation. J Neurol Neurosurg Psychiatry. 2002 Jun;72(6):701-7.

3. Appleby BS, Duggan PS, Regenberg A, Rabins PV. Psychiatric and neuropsychiatric adverse events associated with deep brain stimulation: A meta-analysis of ten years' experience. Mov Disord. 2007 Sep 15;22(12):1722-8.

4. Herzog J, Reiff J, Krack P, Witt K, Schrader B, Muller D, et al. Manic episode with psychotic symptoms induced by subthalamic nucleus stimulation in a patient with Parkinson's disease. Mov Disord. 2003 Nov;18(11):1382-4.

5. Mandat TS, Hurwitz T, Honey CR. Hypomania as an adverse effect of subthalamic nucleus stimulation: report of two cases. Acta Neurochir (Wien). 2006 Aug;148(8):895-7; discussion 8.

6. Bejjani BP, Damier P, Arnulf I, Thivard L, Bonnet AM, Dormont D, et al. Transient acute depression induced by high-frequency deep-brain stimulation. N Engl J Med. 1999 May 13;340(19):1476-80.

7. Mallet L, Schupbach M, N'Diaye K, Remy P, Bardinet E, Czernecki V, et al. Stimulation of subterritories of the subthalamic nucleus reveals its role in the integration of the emotional and motor aspects of behavior. Proc Natl Acad Sci U S A. 2007 Jun 19;104(25):10661-6.

8. Ulla M, Thobois S, Lemaire JJ, Schmitt A, Derost P, Broussolle E, et al. Manic behaviour induced by deep-brain stimulation in Parkinson's disease: evidence of substantia nigra implication? J Neurol Neurosurg Psychiatry. 2006 Dec;77(12):1363-6.

9. American Psychiatric Association. Diagnostic and statistical manual of mental disorders, Text revision (DSM-IV-TR). 4th ed. Washington; 2000.

10. Bech P, Bolwig TG, Kramp P, Rafaelsen OJ. The Bech-Rafaelsen Mania Scale and the Hamilton Depression Scale. Acta Psychiatr Scand. 1979 Apr;59(4):420-30.

11. Sheehan DV, Lecrubier Y, Sheehan KH, Amorim P, Janavs J, Weiller E, et al. The MiniInternational Neuropsychiatric Interview (M.I.N.I.): the development and validation of a structured diagnostic psychiatric interview for DSM-IV and ICD-10. J Clin Psychiatry. 1998;59 Suppl 20:22-33.

12. Fahn S, Elton RL, and Members of the UPDRS development committee. Recent Developments in Parkinson's Disease. Florham Park (NJ): Macmillan Healthcare Information; 1987.

13. Lemaire JJ, Coste J, Ouchchane L, Hemm S, Derost P, Ulla M, et al. Anatomical mapping and direct stereotactic targeting in the subthalamic region: functional and anatomical correspondence in Parkinson's disease Int J CARS. 2007;2:75-85.

14. Caire F, Derost P, Coste J, Bonny JM, Durif F, Frenoux E, et al. [Subthalamic deep brain stimulation for severe idiopathic Parkinson's disease. Location study of the effective contacts]. Neurochirurgie. 2006 Feb;52(1):15-25.

15. Thobois S, Ballanger B, Xie-Brustolin J, Damier P, Durif F, Azulay JP, et al. Globus pallidus stimulation reduces frontal hyperactivity in tardive dystonia. J Cereb Blood Flow Metab. 2008 Jun;28(6):1127-38.

16. Ballanger B, Baraduc $P$, Broussolle $E$, Le Bars D, Desmurget $M$, Thobois S. Motor urgency is mediated by the contralateral cerebellum in Parkinson's disease. J Neurol Neurosurg Psychiatry. 2008 Oct; 79(10):1110-6.

17. Thobois S, Ballanger B, Baraduc P, Le Bars D, Lavenne F, Broussolle E, et al. Functional anatomy of motor urgency. Neuroimage. 2007 Aug 1;37(1):243-52.

18. Oldfield RC. The assessment and analysis of handedness: the Edinburgh inventory. Neuropsychologia. 1971 Mar;9(1):97-113. 
19. Thobois S. Proposed dose equivalence for rapid switch between dopamine receptor agonists in Parkinson's disease: a review of the literature. Clin Ther. 2006 Jan;28(1):1-12.

20. Mattis S. Dementia Rating Scale. Ressources Inc Odessa: Psychological assessment. 1988.

21. Bech P. The Bech-Rafaelsen Mania Scale in clinical trials of therapies for bipolar disorder: a 20-year review of its use as an outcome measure. CNS Drugs. 2002;16(1):47-63.

22. Benazzi F. Challenging DSM-IV criteria for hypomania: diagnosing based on number of nopriority symptoms. Eur Psychiatry. 2007 Oct;22(2):99-103.

23. Derost PP, Ouchchane L, Morand D, Ulla M, Llorca PM, Barget M, et al. Is DBS-STN appropriate to treat severe Parkinson disease in an elderly population? Neurology. $2007 \mathrm{Apr}$ 24;68(17):1345-55.

24. Sato T, Bottlender R, Kleindienst N, Moller HJ. Syndromes and phenomenological subtypes underlying acute mania: a factor analytic study of 576 manic patients. Am J Psychiatry. 2002 Jun;159(6):968-74.

25. Akiskal HS, Azorin JM, Hantouche EG. Proposed multidimensional structure of mania: beyond the euphoric-dysphoric dichotomy. J Affect Disord. 2003 Jan;73(1-2):7-18.

26. Young RC, Biggs JT, Ziegler VE, Meyer DA. A rating scale for mania: reliability, validity and sensitivity. Br J Psychiatry. 1978 Nov;133:429-35.

27. Blumberg HP, Stern E, Martinez D, Ricketts S, de Asis J, White T, et al. Increased anterior cingulate and caudate activity in bipolar mania. Biol Psychiatry. 2000 Dec 1;48(11):1045-52.

28. Caligiuri MP, Brown GG, Meloy MJ, Eyler LT, Kindermann SS, Eberson S, et al. A functional magnetic resonance imaging study of cortical asymmetry in bipolar disorder. Bipolar Disord. 2004 Jun;6(3):183-96.

29. Drevets WC, Price JL, Simpson JR, Jr., Todd RD, Reich T, Vannier M, et al. Subgenual prefrontal cortex abnormalities in mood disorders. Nature. 1997 Apr 24;386(6627):824-7.

30. Goodwin GM, Cavanagh JT, Glabus MF, Kehoe RF, O'Carroll RE, Ebmeier KP. Uptake of $99 \mathrm{mTc}$-exametazime shown by single photon emission computed tomography before and after lithium withdrawal in bipolar patients: associations with mania. Br J Psychiatry. 1997 May;170:42630.

31. Mayberg HS, Lozano AM, Voon V, McNeely HE, Seminowicz D, Hamani C, et al. Deep brain stimulation for treatment-resistant depression. Neuron. 2005 Mar 3;45(5):651-60.

32. Mayberg HS, Liotti M, Brannan SK, McGinnis S, Mahurin RK, Jerabek PA, et al. Reciprocal limbic-cortical function and negative mood: converging PET findings in depression and normal sadness. Am J Psychiatry. 1999 May;156(5):675-82.

33. Botvinick M, Nystrom LE, Fissell K, Carter CS, Cohen JD. Conflict monitoring versus selectionfor-action in anterior cingulate cortex. Nature. 1999 Nov 11;402(6758):179-81.

34. Carter CS, Braver TS, Barch DM, Botvinick MM, Noll D, Cohen JD. Anterior cingulate cortex, error detection, and the online monitoring of performance. Science. 1998 May 1;280(5364):747-9.

35. Elliott R, Rubinsztein JS, Sahakian BJ, Dolan RJ. Selective attention to emotional stimuli in a verbal go/no-go task: an fMRI study. Neuroreport. 2000 Jun 5;11(8):1739-44.

36. Altshuler LL, Bookheimer SY, Townsend J, Proenza MA, Eisenberger N, Sabb F, et al. Blunted activation in orbitofrontal cortex during mania: a functional magnetic resonance imaging study. Biol Psychiatry. 2005 Nov 15;58(10):763-9.

37. Bruno SD, Barker GJ, Cercignani M, Symms M, Ron MA. A study of bipolar disorder using magnetization transfer imaging and voxel-based morphometry. Brain. 2004 Nov;127(Pt 11):2433-40.

38. O'Connell RA, Van Heertum RL, Luck D, Yudd AP, Cueva JE, Billick SB, et al. Single-photon emission computed tomography of the brain in acute mania and schizophrenia. J Neuroimaging. 1995 Apr;5(2):101-4.

39. Migliorelli R, Starkstein SE, Teson A, de Quiros G, Vazquez S, Leiguarda R, et al. SPECT findings in patients with primary mania. J Neuropsychiatry Clin Neurosci. 1993 Fall;5(4):379-83. 
40. Kumari V, Mitterschiffthaler MT, Teasdale JD, Malhi GS, Brown RG, Giampietro V, et al. Neural abnormalities during cognitive generation of affect in treatment-resistant depression. Biol Psychiatry. 2003 Oct 15;54(8):777-91.

41. Behrmann M, Geng JJ, Shomstein S. Parietal cortex and attention. Curr Opin Neurobiol. 2004 Apr;14(2):212-7.

42. Hammond C, Bergman H, Brown P. Pathological synchronization in Parkinson's disease: networks, models and treatments. Trends Neurosci. 2007 Jul;30(7):357-64.

43. Kringelbach ML, Jenkinson N, Owen SL, Aziz TZ. Translational principles of deep brain stimulation. Nat Rev Neurosci. 2007 Aug;8(8):623-35.

44. Gradinaru V, Mogri M, Thompson KR, Henderson JM, Deisseroth K. Optical deconstruction of parkinsonian neural circuitry. Science. 2009 Apr 17;324(5925):354-9.

45. Mclntyre CC, Mori S, Sherman DL, Thakor NV, Vitek JL. Electric field and stimulating influence generated by deep brain stimulation of the subthalamic nucleus. Clin Neurophysiol. 2004 Mar;115(3):589-95.

46. Miocinovic S, Lempka SF, Russo GS, Maks CB, Butson CR, Sakaie KE, et al. Experimental and theoretical characterization of the voltage distribution generated by deep brain stimulation. Exp Neurol. 2009 Mar;216(1):166-76.

47. Schatelbrand G, Wahren W. Atlas for stereotaxy of the human brain. Stuttgart: Thieme; 1977. 48. Haber SN. The primate basal ganglia: parallel and integrative networks. J Chem Neuroanat. 2003 Dec;26(4):317-30.

49. van Domburg PH, ten Donkelaar HJ. The human substantia nigra and ventral tegmental area. A neuroanatomical study with notes on aging and aging diseases. Adv Anat Embryol Cell Biol. 1991;121:1-132. 


\section{Titles and legends of the figures}

Figure 1: illustration of 3D anatomical location of electrodes (e.g. of patient 2).

A: frontal view of the electrodes (in blue) with the different contacts (in yellow) and 3D view of the subthalamic area with the subthalamic nucleus (in yellow) and the substantia nigra (in blue). Each electrode had four contacts (length $1.5 \mathrm{~mm}$ ) separated by $0.5 \mathrm{~mm}$ intervals, and numbered from 0 to 3 in the right hemisphere and from 4 to 7 in the left hemisphere, where 0 and 4 correspond to the deepest contacts. This representation is superimposed on a coronal T2-weighted MRI (preoperative MRI of the patient) to illustrate the location of SN and STN in the basal ganglia environment.

STN: subthalamic nucleus, SN: substantia nigra, Th: Thalamus, TL: temporal lobe.

B: frontal view of the subthalamic area.

C: Left antero-lateral view of right STN area and D: Right antero-lateral view of left STN area, allowing to see the "manic" contacts within SN for patient 2.

In figure $1 \mathbf{B , C , D}$, the STN (yellow) and the SN (blue) are represented in transparency with the "manic" contacts in red and the "euthymic" contacts in green.

Figure 2: 3D anatomical contact locations of each patient on frontal, lateral and top views. The SN is represented in blue, the STN in yellow, and the contacts in grey. "Euthymic" contacts are in green and "manic" contacts in red (not represented in top view).

Figure 3: PET scan data (see text for details).

A, B: Increased activation in hypomanic compared to euthymic state in the dorsal anterior cingulate cortex (BA 24-32) (A, crossing blue lines) and right medial prefrontal cortex (BA10) (B, crossing blue lines).

C: Decreased activation in hypomanic compared to euthymic state in left temporal cortex (BA $21,39,20)$ and bilaterally in occipital cortex (BA 18, 19, 17).

These regions are superimposed on a single-subject brain MRI derived from SPM2. R=right; $\mathrm{L}=$ left. 


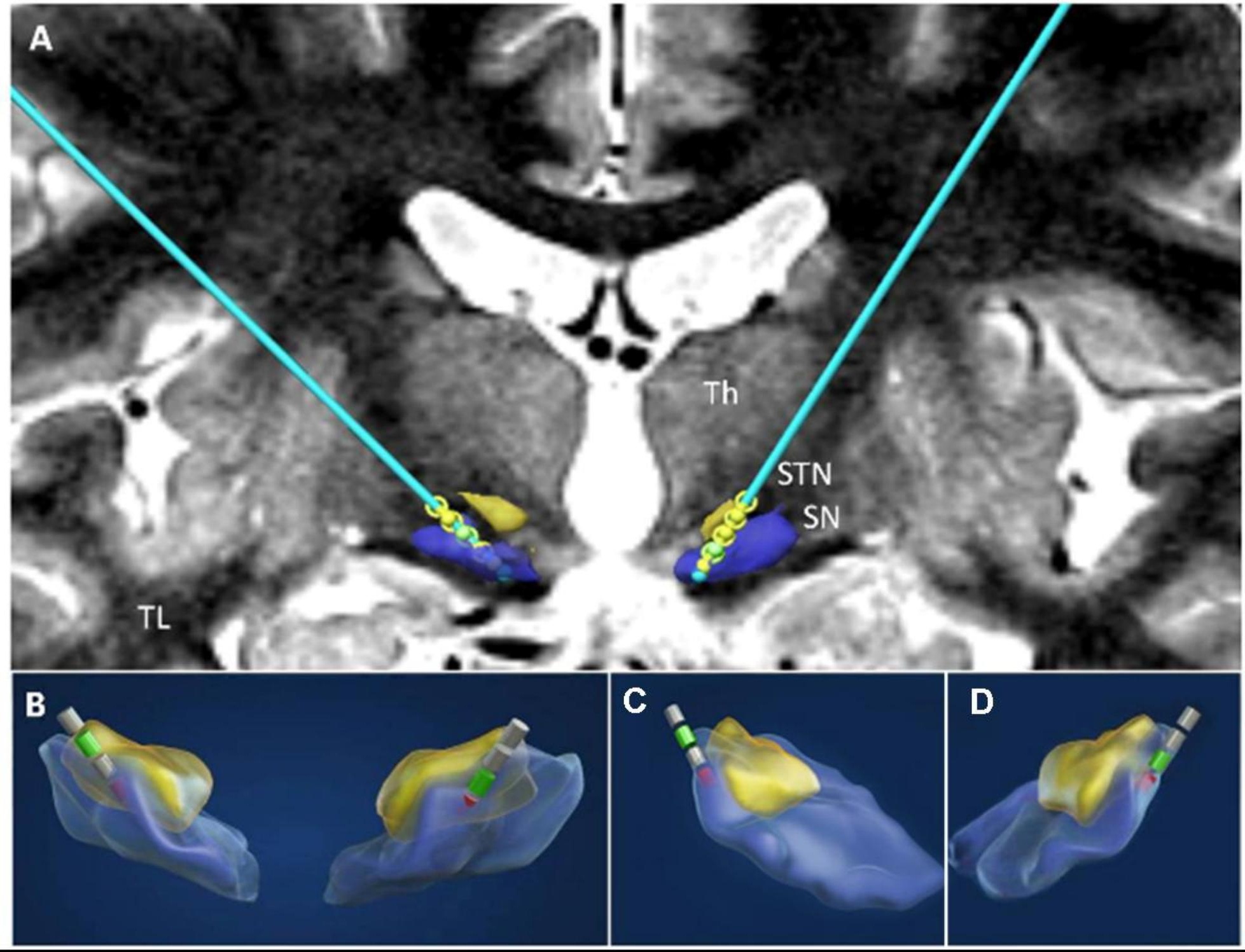



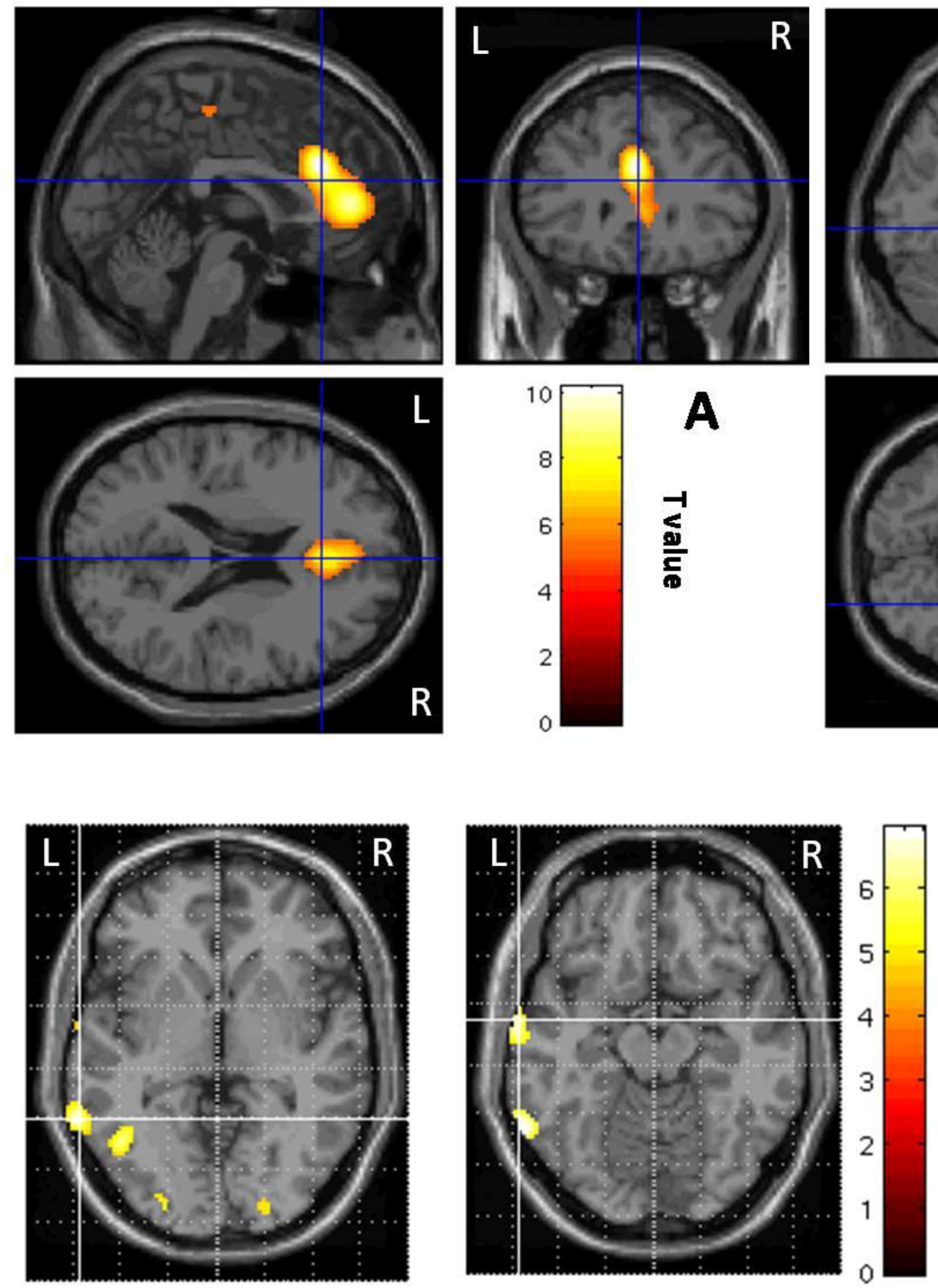
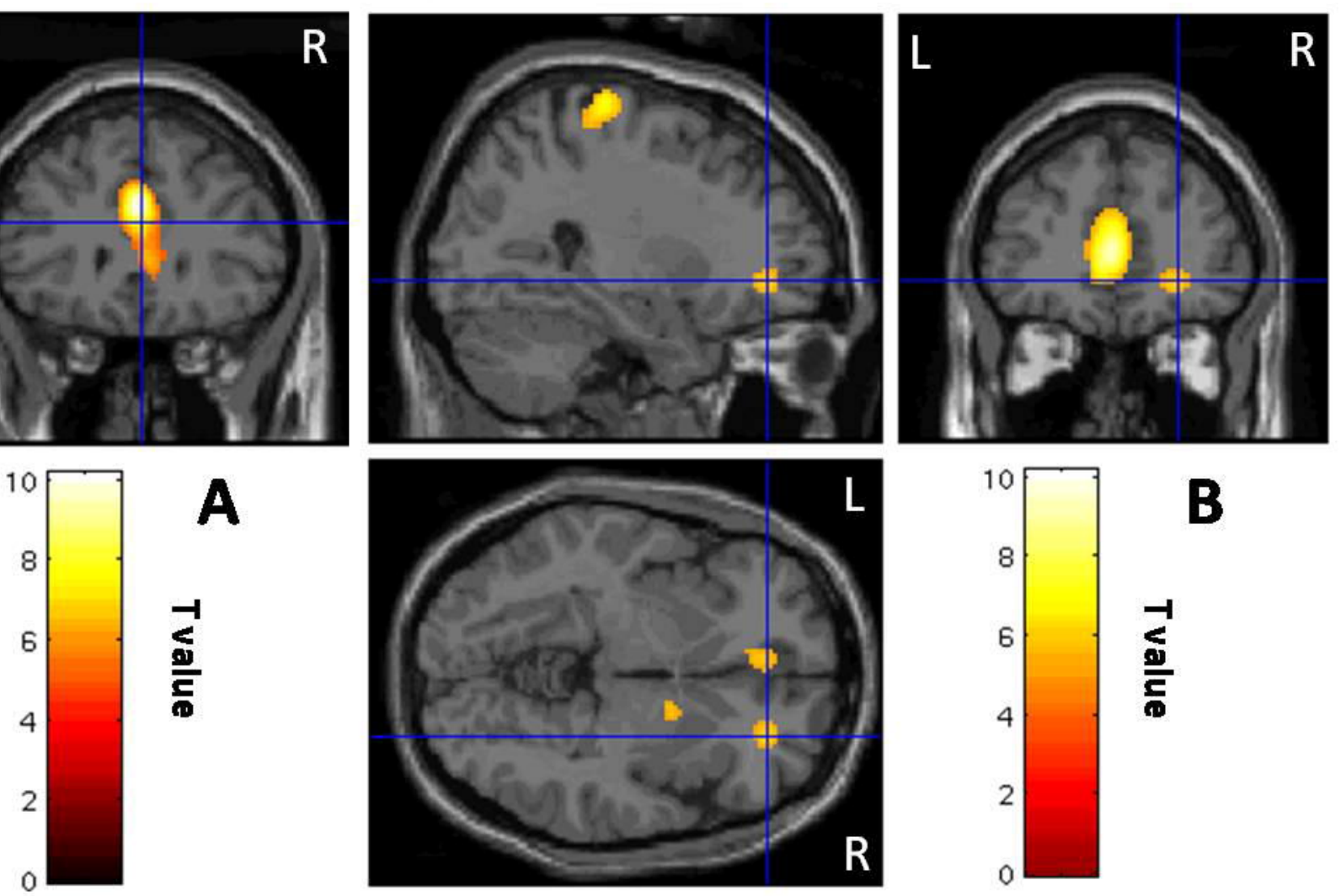

A

홍
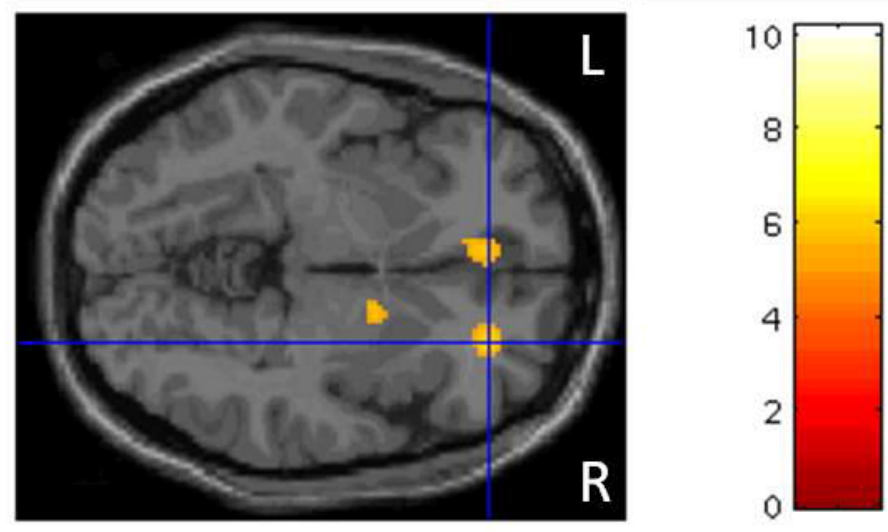

B

志

C

ํㅗำ

R

3

I.

B

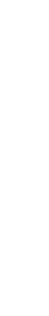

c

$\frac{-1}{5}$ 